lábio palatina submetido a expansão lenta maxilar. Descrição do caso clínico: Doente do sexo feminino, 15 anos de idade, apresentou-se à consulta do Instituto de Ortodontia da Faculdade de Medicina da Universidade de Coimbra para correção da má oclusão associada à fenda lábio-palatina esquerda. A doente foi submetida a queiloplastia aos 4 meses e a uranoplastia aos 3 anos de idade. À observação intra-oral, apresentava: classe I de angle à direita e classe II à esquerda; mordida cruzada posterior esquerda; agenesia do 22; e apinhamento anterior na arcada inferior. O plano de tratamento consistiu num aparelho expansor (quad-helix), seguido de enxerto ósseo secundário e, posteriormente aparatologia fixa multibrackets roth 0,18 . Discussão e conclusões: A expansão maxilar contribui para o aumento da largura da cavidade nasal, do maxilar e, consequentemente da fenda palatina. O protocolo de expansão rápida e lenta são ambos eficazes no tratamento da discrepância transversal em doentes portadores de fenda lábio palatina. No entanto, o protocolo de expansão lenta preconiza forças mais leves e contínuas, o que permite uma maior integridade sutural durante a expansão, menor dano e hemorragia, desprogramação da postura e resultados mais estáveis a longo prazo. Estes fatores possibilitam uma terapêutica mais cómoda e menos dolorosa para os doentes. Em doentes portadores de fenda lábio palatina, a escolha pela expansão maxilar lenta, permite uma expansão mais fisiológica, evitando a necrose/dano dos tecidos adjacentes à região da fenda.

http://doi.org/10.24873/j.rpemd.2020.12.746

\section{\#023 Lipoma da cavidade oral- A propósito de um caso clínico}

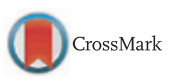

Carina Pires Gonçalves*, Eduardo Simões Ventura, Hugo Martins Marques, Sílvia Dionísio, Nuno Durão, Miguel Vicente

\section{Centro Hospitalar e Universitário do Porto}

Introdução: Lipomas são os tumores benignos mesenquimais mais comuns, compostos de adipócitos maduros. São frequentes na região de cabeça e pescoço, mas raros na cavidade oral, representando $1 \%$ a $4 \%$ das lesões benignas nesta cavidade. A mucosa jugal é a localização mais habitual. Apresentam maior incidência no sexo feminino e entre a $4 .^{\circ}$ e a 7. ${ }^{\circ}$ década de vida. A sua etiologia é idiopática. O lipoma simples e o fibrolipoma, são as variantes histopatológicas mais comuns, na cavidade oral. Descrição do caso clínico: Doente do sexo masculino, com 49 anos, é referenciado à consulta externa de Cirurgia Maxilo-Facial, por massa na região mandibular direita, com crescimento progressivo ao longo de 2 anos. O doente apresenta ao exame objetivo apenas abaulamento da mucosa jugal direita. Esta massa é unitária e séssil, indolor, consistência elástica e infiltração profunda à palpação, com $6-7 \mathrm{cms}$ de diâmetro e de limites bem definidos. Foi realizada ecografia e TC maxilo-facial, com posterior excisão total da lesão, via endobucal, sem intercorrências. O exame anatomopatológico estabeleceu o diagnóstico definitivo de lipoma simples. O doente não apresenta danos morfológicos, funcionais ou recidiva. Discussão e conclusões: Perante os dados epidemiológicos, o quadro clínico e as características da lesão, o diagnóstico a ser colocado é de lipoma. No entanto, há que equacionar outros diagnósticos, dada a profundidade da lesão, como: fibroma, tumor de células granulares, neoplasia de glândulas salivares, quisto dermoide, quisto linfoepitelial oral e outros tumores benignos dos tecidos moles. O diagnóstico de lipoma é clínico sendo o diagnóstico definitivo estabelecido pelo exame anatomopatólogico. Esta hipótese diagnóstica é sustentada por o quadro clínico ser insidioso e por esta lesão ser unitária, mole, indolor e com crescimento lento. Apesar dos lipomas poderem ocorrer em todas idades, são mais frequentes entre a $4 .^{\circ}$ e a $7 .^{\circ}$ década de vida, o que apoia esta hipótese. Também a localização da lesão, corrobora a hipótese de lipoma, porque, apesar de poderem ser encontrados em várias localizações (lábio inferior, região retromolar, língua, pavimento, palato), a mucosa jugal é a localização mais frequente. Apesar do crescimento dos lipomas orais ser limitado, podem atingir grandes dimensões, o que pode interferir com a fala e a mastigação havendo a necessidade de tratamento. A excisão cirúrgica simples é o tratamento de eleição, sendo a recidiva e a transformação maligna raras.

http://doi.org/10.24873/j.rpemd.2020.12.747

\section{\#024 Eritroleucoplasia - a propósito de um caso clínico}

Olga Vascan*, Maria J. Morais, Ana M. Marques, João M. Oliveira, Francisco J. D. Marques, José P. Figueiredo

Serviço de Estomatologia - Centro Hospitalar e Universitário de Coimbra; Serviço de Cirurgia Maxilo-Facial - Centro Hospitalar e Universitário de Coimbra

Introdução: Eritroleucoplasia é definida pela OMS como uma placa ou mancha branca e vermelha que não corresponde clínica ou histologicamente a nenhuma doença conhecida". É uma lesão oral rara, de etiologia desconhecida, em que o tabaco, o álcool e a nutrição, combinados ou não, parecem ser factores predisponentes. A taxa de malignização varia consoante os estudos, sendo reportados valores entre $5,2 \%$ e $55 \%$, com taxas mais elevadas nos não fumadores. Localiza-se com mais frequência na língua, comissuras labiais e pavimento bucal, podendo ou não estar associada a dor ou disfagia. Descrição do caso clínico: Senhora de 62 anos, observada na consulta externa Serviço de Estomatologia por lesão leuco-eritematosa da língua com cerca de 6 meses de evolução, indolor. Sem antecedentes pessoais e familiares relevantes. Ao exame clínico, observou-se placa leuco-eritroplásica no bordo esquerdo da língua, textura rugosa, de consistência mole, depressível, não infiltrada com cerca de 4,5 x $3 \mathrm{~cm}$. Na primeira consulta, com base na história clínica e exame objetivo estabelece-se um diagnóstico clínico de eritroleucoplasia. Foi explicada a situação à doente e procedeu-se a um desgaste selectivo dos dentes contíguos para eliminar qualquer traumatismo. Após 3 semanas, marcou-se consulta de reavaliação, não se observou regresssão da lesão. Foi decidido realizar biopsia excisional da lesão, e envio da peça para estudo anatomo-patológico. O re- 